\title{
Estimação da Digestibilidade Intestinal da Proteína de Alimentos por Intermédio da Técnica de Três Estádios
}

\author{
Luciano da Silva Cabral ${ }^{1}$, Sebastião de Campos Valadares Filho², Pedro Antônio Muniz \\ Malafaia $^{3}$, Rogério de Paula Lana ${ }^{2}$, José Fernando Coelho da Silva ${ }^{4}$, Ricardo Augusto \\ Mendonça Vieira ${ }^{5}$, Elzânia Sales Pereira ${ }^{6}$
}

\begin{abstract}
RESUMO - O objetivo do presente trabalho foi estimar a digestibilidade intestinal da proteína não-degradada no rúmen de alimentos por intermédio da técnica de três estádios. Os alimentos avaliados foram os farelos de soja, algodão e trigo; fubá e glúten de milho; grão de soja e caroço de algodão; e farinhas de peixe, carne e sangue. Os alimentos foram inicialmente incubados no rúmen de bovinos fistulados, por 16 horas para determinação da proteína não-degradada no rúmen (PNDR), sendo o resíduo submetido à digestão com solução de pepsina, durante 1 hora, e solução de pancreatina a $38^{\circ} \mathrm{C}$, durante 24 horas, cujos resíduos foram analisados para nitrogênio total (N). A estimativa da PNDR variou de 18,83 a 94\% e a digestibilidade intestinal da PNDR, de 25,07 a 83,25\%. O glúten de milho e o farelo de soja foram os alimentos que apresentaram a melhor digestibilidade intestinal e o grão de soja e o farelo de trigo, a pior digestibilidade. Embora alguns sistemas de adequação de dietas para ruminantes considerem que a PNDR apresenta digestibilidade intestinal constante, os resultados encontrados neste estudo sugerem que esta foi variável.
\end{abstract}

Palavras-chave: digestibilidade, intestinos, proteína, ruminante

\section{Estimation of Protein Intestinal Digestibility of Feeds by Means of Three-steps Technique}

\begin{abstract}
The objective of this research was to estimate the intestinal digestibility of rumen-undegradable protein (RUDP) by a three-steps procedure. The evaluated feeds were the soybean meal, cottonseed meal, wheat middlings, corn meal, corn gluten meal, whole raw soybean, whole raw cottonseed, fishmeal, meat meal and blood meal. Firstly, the feeds were incubated in rumen during 16 hours to determine the rumen-undegradable protein, the residue was incubated with pepsin solution during 1 hour, and pancreatic solution during 24 hours at $38^{0} \mathrm{C}$, whose residues were analyzed for total nitrogen. The RUDP ranged from $18,83 \%$ to $94 \%$, and the estimates of intestinal digestion of RUDP ranged from 25,07 to $83,25 \%$. The corn gluten meal and soybean meal were the feeds that presented better intestinal digestibility, and the whole raw soybean and wheat middlings, the lowest digestibility. Although some formulation systems for ruminant diets suggest that the RUDP presents constant intestinal digestibility, the data obtained in this study suggest that this was changeable.
\end{abstract}

Key Words: digestibility, small intestine, protein, ruminant

\section{Introdução}

As exigências em proteína metabolizável dos ruminantes são atendidas pela proteína microbiana produzida no rúmen, proteína dietética que escapa à fermentação ruminal e proteína endógena (DE BOER et al., 1987; BRODERICK, 1995). A proteína microbiana contribui com $50 \%$ ou mais dos aminoácidos disponíveis para absorção no intestino delgado, sendo considerada fonte protéica de boa qualidade, uma vez que apresenta elevada digestibilidade intestinal e seu perfil aminoacídico se assemelha ao dos tecidos e da prote- ína do leite (SCHWAB, 1996). Já a proteína dietética não-degradada no rúmen apresenta composição em aminoácidos e digestibilidade intestinal variável.

É desejável que a proteína dietética seja degradada no rúmen e, então, convertida em proteína microbiana, quando apresentar baixa qualidade. Entretanto, quando se trata de fontes protéicas de elevado valor biológico, deve-se minimizar sua degradação ruminal, de modo que esta seja em sua maior parte digerida no intestino delgado, evitando possíveis perdas em aminoácidos essenciais no rúmen decorrentes da fermentação (VAN SOEST, 1994).

\footnotetext{
1 Estudante de Doutorado da UFV/DZO, 36571-000 - Viçosa-MG. E.mail: Iscabral@alunos.ufv.br

2 Professor da UFV/DZO, 36571-000 - Viçosa-MG

3 Professor da UFRRJ-IZ-DNAP, 23851-970 - Seropédica-RJ. E.mail: malafaia@ufrrj.br.

4 Professor da UENF-CCTA-LZNA, Campos dos Goytacazes-RJ.

5 Pesquisador do Instituto Melon de Paula, Anápolis-Go.

6 Professora da UNIOESTE-DPA, PR.
} 
Sendo a proteína microbiana relativamente constante em sua composição, a única alternativa para alteração do perfil de aminoácidos da digesta duodenal é por meio do aumento de fontes protéicas que escapam à degradação ruminal (SCHWAB, 1996). Entretanto, a utilização de fontes protéicas de baixa degradação no rúmen, em substituição às fontes de maior degradação, em muitos estudos, tem resultado em falta de respostas, ou até respostas negativas, no desempenho dos animais. As possíveis razões para este fato são a redução da síntese de proteína microbiana e a inclusão de fontes de PNDR com perfil pobre em aminoácidos essenciais ou com baixa digestibilidade intestinal, ou as dietas controle já são suficientemente elevadas em PNDR (CLARK et al., 1992; SCHWAB et al., 1992a).

Embora a proteína microbiana seja excelente fonte de aminoácidos para o animal, a quantidade que atinge o duodeno não é suficiente para atender as elevadas exigências de alguns animais, principalmente vacas leiteiras de alta produção. Dessa forma, para o atendimento do débito protéico não-suprido pela proteína microbiana, torna-se necessária a inclusão de fontes protéicas de maior escape ruminal.

Embora os sistemas de adequação de dietas para ruminantes (NATIONAL RESEARCH COUNCIL NRC, 1985; AGRICULTURAL AND FOOD RESEARCH COUNCIL - AFRC, 1993) considerem constante a digestibilidade intestinal da proteína que escapa à fermentação ruminal, tem sido constatado que esta varia grandemente entre as fontes. Dessa forma, pode-se cometer erros a partir desta pressuposição, tornando-se necessária a estimação mais exata da digestibilidade intestinal da proteína de cada alimento. Entretanto, sua determinação é relativamente cara e laboriosa e ainda requer a utilização de animais canulados em várias seções do trato gastrintestinal. Vários métodos alternativos têm sido desenvolvidos para essas estimativas, entre os quais se destacam a técnica do saco de náilon móvel (HVELPLUND, 1985), a determinação do N insolúvel em detergente ácido (GOERING et al., 1972), os procedimentos enzimáticos (Britton et al., 1986, citados por CALSAMILGIA e STERN, 1995) e o teste da disponibilidade da lisina (FALDET et al., 1991). Porém, estes métodos têm falhado no que diz respeito à simulação das condições fisiológicas dos ruminantes, pois não incluem o potencial efeito da fermentação ruminal e, adicionalmente, são demorados e caros, não podem ser aplicados à grande variedade de alimentos e não refletem de forma exata as diferen- ças na digestão intestinal entre os alimentos (CALSAMIGLIA e STERN, 1995). A técnica de três estádios foi desenvolvida com base nos conceitos citados anteriormente e vem sendo testada como método para estimar a digestibilidade intestinal de alimentos protéicos.

Portanto, o objetivo do presente trabalho foi estimar a digestibilidade intestinal da proteína de alimentos freqüentemente utilizados no Brasil como fonte de proteína não-degradada no rúmen.

\section{Material e Métodos}

Os alimentos avaliados foram os farelos de soja, algodão e trigo; o glúten e o fubá de milho; o caroço de algodão e o grão de soja; e as farinhas de peixe, sangue e carne. Inicialmente, foram feitas as análises laboratoriais convencionais destes alimentos, incluindo matéria seca (MS), proteína bruta (PB), cinzas $(\mathrm{MM})$ e extrato etéreo (EE) conforme ASSOCIATION OF OFFICIAL ANALYTICAL CHEMISTS - AOAC, 1990, cuja composição bromatológica consta na Tabela 1.

A proteína não-degradada no rúmen (PNDR) foi estimada pela incubação ruminal de cerca de $5 \mathrm{~g}$ de amostra dos concentrados, moídos em moinho com porosidade da peneira de $2 \mathrm{~mm}$, por meio de sacos de náilon, conforme NOCEK (1988), durante 16 horas, em dois bovinos fistulados no rúmen alimentados com dieta composta de 70:30 volumoso:concentrado. A quantidade de amostra incubada dependeu do seu teor em compostos nitrogenados $(\mathrm{N})$, pois o resíduo da incubação ruminal deve conter, no mínimo, $60 \mathrm{mg}$ de N. Após a incubação ruminal, os sacos foram lavados em água corrente até que a água de enxágüe se tornasse clara e, então, colocados em estufa de ventilação forçada durante 48 horas a $55^{\circ} \mathrm{C}$.

A simulação da digestão intestinal da PNDR foi realizada conforme CALSAMIGLIA e STERN (1995). Os resíduos da incubação ruminal foram analisados para $\mathrm{N}$ e pesados de maneira a proporcionar aproximadamente $15 \mathrm{mg}$ de $\mathrm{N}$ e colocados em erlemeyers de $125 \mathrm{~mL}$. Posteriormente, estes foram incubados com $10 \mathrm{~mL}$ de uma solução $0,1 \mathrm{~N}$ de $\mathrm{HCl}$ contendo $1 \mathrm{~g} / \mathrm{L}$ de pepsina $(\mathrm{pH}=1,9)$ durante 1 hora a $38^{\circ} \mathrm{C}$. Posteriormente, foram adicionados $0,5 \mathrm{~mL}$ de solução $1 \mathrm{~N}$ de $\mathrm{NaOH}$ para neutralização do $\mathrm{pH}$ e $13,5 \mathrm{~mL}$ de solução de pancreatina $(0,5 \mathrm{M}$ de solução de $\mathrm{KH}_{2} \mathrm{PO}_{4}, \mathrm{pH}=7,8$ ) contendo $50 \mathrm{ppm}$ de thymol, para prevenir o crescimento microbiano, e $3 \mathrm{~g} / \mathrm{L}$ de pancreatina durante 24 horas. Ao final da digestão, os 
548 Rev. bras. zootec.

Tabela 1 - Porcentagem de matéria seca (MS), proteína bruta (PB), cinzas (MM), extrato etéreo (EE) e fibra insolúvel em detergente neutro (FDN) de alguns alimentos protéicos

Table 1 - Porcentage of dry matter, crude protein, ash, ether extract and neutral detergent fiber of some protein feedstuffs

\begin{tabular}{|c|c|c|c|c|c|}
\hline \multirow[t]{2}{*}{$\begin{array}{l}\text { Alimentos } \\
\text { Feeds }\end{array}$} & \multirow[t]{2}{*}{$\begin{array}{l}\mathrm{MS}(\%) \\
D M(\%)\end{array}$} & \multicolumn{4}{|c|}{$\begin{array}{l}\text { Porcentagem na MS } \\
\text { Percentage of the dry matter }\end{array}$} \\
\hline & & $\begin{array}{l}\mathrm{PB} \\
C P\end{array}$ & $\begin{array}{l}\mathrm{MM} \\
\text { Ash } \\
\end{array}$ & $\mathrm{EE}$ & $\begin{array}{l}\mathrm{FDN} \\
N D F \\
\end{array}$ \\
\hline $\begin{array}{l}\text { Glúten de milho } \\
\text { Corn gluten meal }\end{array}$ & 90,85 & 62,36 & 1,71 & 1,34 & 6,46 \\
\hline $\begin{array}{l}\text { Farelo de soja } \\
\text { Soybean meal }\end{array}$ & 88,08 & 50,88 & 5,62 & 1,73 & 13,17 \\
\hline $\begin{array}{l}\text { Farinha de carne } \\
\text { Meat meal }\end{array}$ & 91,32 & 89,86 & 1,40 & 6,29 & - \\
\hline $\begin{array}{l}\text { Farinha de peixe } \\
\text { Fish meal }\end{array}$ & 94,00 & 55,38 & 27,52 & 1,89 & - \\
\hline $\begin{array}{l}\text { Farinha de sangue } \\
\text { Blood meal }\end{array}$ & 95,70 & 87,25 & 2,97 & 4,42 & - \\
\hline $\begin{array}{l}\text { Fubá de milho } \\
\text { Corn meal }\end{array}$ & 89,27 & 8,54 & 1,24 & 5,80 & 10,52 \\
\hline $\begin{array}{l}\text { Farelo de algodão } \\
\text { Cottonseed meal }\end{array}$ & 88,96 & 31,9 & 5,63 & 1,48 & 43,05 \\
\hline $\begin{array}{l}\text { Caroço de algodão } \\
\text { Whole raw cottonseed }\end{array}$ & 88,05 & 21,51 & 4,04 & 27,83 & 34,79 \\
\hline $\begin{array}{l}\text { Farelo de trigo } \\
\text { Wheat middlings }\end{array}$ & 87,27 & 17,44 & 5,77 & 2,67 & 40,0 \\
\hline $\begin{array}{l}\text { Grão de soja } \\
\text { Whole raw soybean }\end{array}$ & 89,56 & 46,83 & 5,26 & 17,14 & 14,51 \\
\hline
\end{tabular}

resíduos foram imediatamente filtrados em papelfiltro, lavados com $400 \mathrm{~mL}$ de água destilada, e o $\mathrm{N}$ residual determinado pelo método Kjeldahl. A digestibilidade intestinal da proteína não-degradada no rúmen, em porcentagem, foi calculada como a quantidade de $\mathrm{N}$ digerido após incubação com pepsina e pancreatina multiplicado por 6,25 , o qual foi dividido pela quantidade de proteína incubada e multiplicado por 100. A partir do porcentual de digestão intestinal da PNDR, foram calculados a porcentagem e o teor de proteína não-degradada no rúmen digestível no intestino delgado $\left(\mathrm{PNDR}_{\mathrm{D}}\right)$.

\section{Resultados e Discussão}

A degradação ruminal e a digestão intestinal da proteína bruta (PB) dos alimentos estudados são apresentadas na Tabela 2 . A porcentagem de proteína degradada no rúmen (PDR) variou de 6 a 81,17\%, para a farinha de sangue e o grão de soja, respectivamente, estando estes valores de acordo com os existentes na literatura (MASOERO et al., 1994; ERASMUS et al., 1994; STERN et al., 1994; RAMOS et al., 1996; e VALADARES FILHO, 1997). As estimativas da
PNDR para o glúten de milho, o farelo de trigo e o farelo de soja são semelhantes às obtidas por MORENZ et al. (1998), por meio da técnica in situ.

As fontes protéicas de origem animal destacaram-se pela baixa degradação ruminal, sendo, portanto, indicadas como fontes de alto escape, entretanto, sua utilização eficiente depende da digestão intestinal da proteína (Tabela 2 e Figura 1). A farinha de sangue destacou-se pela elevada proporção de PNDR, o que também foi encontrado por PIEPENBRINK e SCHINGOETHE (1998) e CALSAMIGLIA e STERN (1995). Entre as fontes protéicas de origem vegetal, o farelo de glúten de milho destacou-se pela elevada resistência à degradação ruminal $(18 \%$ de PDR), o que também tem sido indicado por outros autores (STERN et al., 1994; MORENZ et al., 1998). Já o grão de soja destacou-se pela elevada degradação no rúmen (Tabela 2 e Figura 2), merecendo atenção especial quando da sua utilização em proporções significativas na dieta, uma vez que pode conduzir a grandes perdas de $\mathrm{N}$ no rúmen, tornando necessária a inclusão de fontes energéticas de rápida degradação.

Quanto à digestão intestinal da PNDR, os valores encontrados neste estudo variaram de 25,07a 83,25\%, 
para o grão de soja e o glúten de milho, respectivamente (Tabela 2 e Figura 1). O glúten de milho e o farelo de soja são os alimentos que se destacaram por apresentarem elevada digestibilidade intestinal. Entre as fontes de origem animal, a farinha de carne destacou-se pela elevada digestão intestinal (DI), a qual está próxima à DI encontrada para o glúten de milho e do farelo de soja.

As digestibilidades intestinais da PNDR do farelo de glúten de milho e do farelo de soja, ainda que sejam as maiores estimativas numéricas obtidas neste estudo, foram inferiores aos valores de 95 e 99,3\% relatados por DE BOER et al. (1987), de 97,6 e $98 \%$ por ERASMUS et al. (1994), respectivamente, e de 97,2\% para o farelo de soja encontrado por RAMOS et al. (1996), obtidos pela técnica do saco de náilon móvel. Entretanto, estes valores estão mais próximos aos encontrados por STERN et al. (1994), com o farelo de soja, de 88 e $89 \%$ obtidos por meio da técnica de três estádios in vitro. Estas diferenças entre as estimativas obtidas pelas duas técnicas podem ser atribuídas ao efeito da fermentação microbiana no intestino grosso sob a proteína não-digerida no intestino delgado presente nos sacos de náilon, o que tende a aumentar as estimativas da digestibilidade intestinal pela técnica do saco de náilon móvel. HVELPUND (1985) constatou que a quantidade de proteína do farelo de soja no interior dos sacos que foi digerida no intestino grosso foi $50 \%$ daquela que deixava o íleo.

A digestão intestinal da PNDR da farinha de peixe apresenta grande variação de valores na literatura, variando de 55,8 a $95,5 \%$, e o valor obtido neste estudo $(73,37 \%)$ está dentro desta variação. No caso da farinha de sangue, a digestibilidade intestinal obtida $(67,82 \%)$ está próxima ao valor de $63 \%$ observado por STERN et al. (1994) e, da mesma forma que para a farinha de peixe, há grande variação das estimativas na literatura, as quais se estendem de 26,5 a $76,57 \%$ (ERASMUS et al., 1994; MASOERO et al., 1994; STERN et al., 1994; e VALADARES FILHO, 1997).

Os valores encontrados para a digestibilidade intestinal da PNDR do fubá de milho, farelo de algodão, caroço de algodão e farelo de trigo foram bastante inferiores aos relatados pela literatura (ERASMUS et al., 1994; MASOERO et al., 1994; STERN et al., 1994; e VALADARES FILHO, 1997). Este fato pode ser atribuído à elevada degradação ruminal destas fontes, com exceção da proteína do milho. Dessa forma, a proteína que escapa do rúmen

Tabela 2 - Teores de proteína bruta (PB), proteína degradada no rúmen (PDR) e proteína não-degradada no rúmen (PNDR) para 16 horas de incubação ruminal, digestibilidade intestinal da PNDR (DI) e PNDR digestível no intestino delgado $\left(\right.$ PNDR $\left._{\mathrm{D}}\right)$

Table 2 - Contents of crude protein, rumen-degradable protein and rumen-undegradable protein (RUDP) for 16 hours of ruminal incubation, intestinal digestibility of RUDP and digestible RUDP in the small intestine

\begin{tabular}{|c|c|c|c|c|c|c|}
\hline \multirow{2}{*}{$\begin{array}{l}\text { Alimentos } \\
\text { Feeds }\end{array}$} & $\begin{array}{l}\mathrm{PB} \\
C P\end{array}$ & $\begin{array}{l}\text { PDR } \\
R D P\end{array}$ & $\begin{array}{l}\text { PNDR } \\
R U D P\end{array}$ & \multirow{2}{*}{$D I$} & $\begin{array}{l}\mathrm{PNDR}_{\mathrm{D}} \\
R U D P_{D}\end{array}$ & \multirow{2}{*}{$\begin{array}{r}\mathrm{PNDR}_{\mathrm{D}} \\
R U D P_{D} \\
(\mathrm{~g} / \mathrm{kg} \mathrm{MS}) \\
\end{array}$} \\
\hline & $(\% \mathrm{MS})$ & \multicolumn{2}{|c|}{$(\% \mathrm{~PB})$} & & (\%) & \\
\hline Glúten de milho & 62,36 & 18,00 & 82,00 & 83,25 & 68,27 & 426 \\
\hline $\begin{array}{l}\text { Corn gluten meal } \\
\text { Farelo de soja } \\
\text { Sovbean meal }\end{array}$ & 50,88 & 50,86 & 49,14 & 82,68 & 40,63 & 207 \\
\hline $\begin{array}{l}\text { Farinha de carne } \\
\text { Meat meal }\end{array}$ & 89,86 & 7,62 & 92,38 & 79,30 & 73,26 & 658 \\
\hline $\begin{array}{l}\text { Farinha de peixe } \\
\text { Fish meal }\end{array}$ & 55,38 & 11,07 & 88,93 & 73,37 & 65,25 & 361 \\
\hline $\begin{array}{l}\text { Farinha de sangue } \\
\text { Blood meal }\end{array}$ & 87,25 & 6,00 & 94,00 & 67,82 & 63,75 & 556 \\
\hline $\begin{array}{l}\text { Fubá de milho } \\
\text { Corn meal }\end{array}$ & 8,54 & 30,00 & 70,00 & 56,19 & 39,33 & 33 \\
\hline $\begin{array}{l}\text { Farelo de algodão } \\
\text { Cottonseed meal }\end{array}$ & 31,9 & 64,71 & 35,29 & 53,66 & 18,94 & 60 \\
\hline $\begin{array}{l}\text { Caroço de algodão } \\
\text { Whole raw cottonseed }\end{array}$ & 21,51 & 68,86 & 31,14 & 39,94 & 12,44 & 27 \\
\hline $\begin{array}{l}\text { Farelo de trigo } \\
\text { Wheat middlings }\end{array}$ & 17,44 & 76,95 & 23,05 & 38,18 & 8,80 & 15 \\
\hline $\begin{array}{l}\text { Grão de soja } \\
\text { Whole raw soybean }\end{array}$ & 46,83 & 81,17 & 18,83 & 25,07 & 4,72 & 22 \\
\hline
\end{tabular}


550 Rev. bras. zootec.

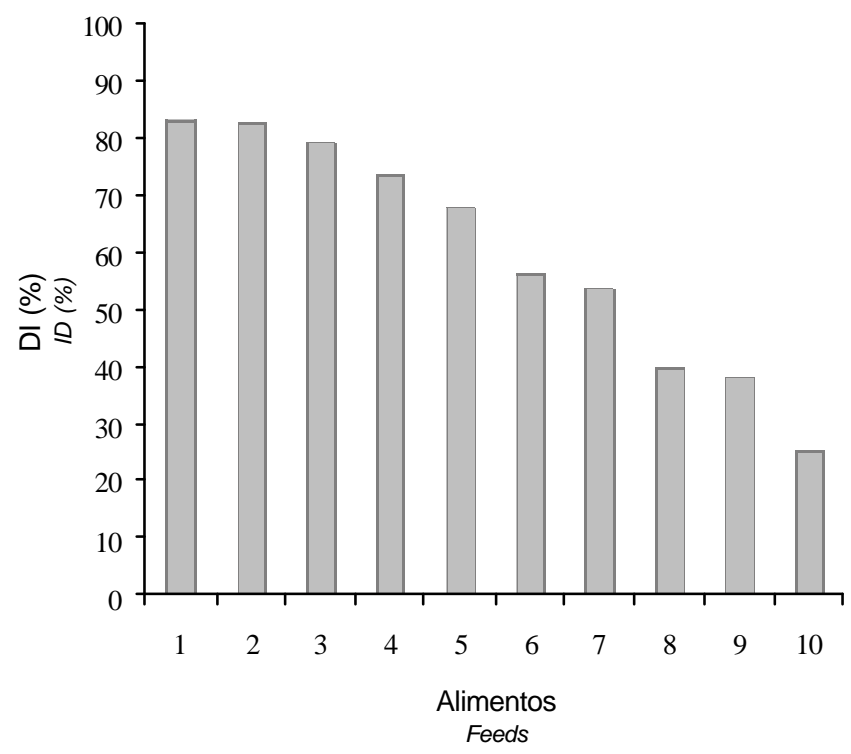

Figura 1 - Digestibilidade intestinal (DI) da proteína PNDR do glúten de milho (1), farelo de soja (2), farinha de carne (3), farinha de peixe (4), farinha de sangue (5), fubá de milho (6), farelo de algodão (7), caroço de algodão (8), farelo de trigo (9) e grão de soja (10).

Figure 1 - Intestinal digestibility (ID) of rumen-undegradable protein from corn gluten meal (1), soybean meal (2), meat meal (3), fish meal (4), blood meal (5) corn meal (6), cottonseed meal (7), whole raw cottonseed (8), wheat middlings (9) and whole raw soybean (10).

corresponde à fração de mais difícil digestão. No caso particular do farelo de algodão, do caroço de algodão e do farelo de trigo, os quais apresentaram elevado teor em FDN (Tabela 1), é possível que a proteína que escapa à fermentação ruminal esteja associada à fibra, o que explica a baixa digestão no intestino delgado.

Na Tabela 2, também é apresentado o teor ( $\mathrm{g} / \mathrm{kg}$ MS) de proteína não-degradada no rúmen e digestível no intestino delgado $\left(\mathrm{PNDR}_{\mathrm{D}}\right)$. Os alimentos que forneceram o maior teor de $\mathrm{PNDR}_{\mathrm{D}}$ são as farinhas de carne e sangue, devido ao elevado teor de proteína bruta e ao elevado escape desta do rúmen, e, no caso particular da farinha de carne, também se deve à sua elevada digestão intestinal, uma vez que a farinha de sangue apresentou digestibilidade intestinal intermediária. Os alimentos de maior degradação no rúmen propiciaram os menores teores em $\mathrm{PNDR}_{\mathrm{D}}$, com exceção do fubá de milho, que, apesar de fornecer baixa $\mathrm{PNDR}_{\mathrm{D}}$, apresentou elevada resistência à degradação ruminal. O glúten de milho, entre as fontes de origem vegetal, foi o que propiciou o maior teor de $\mathrm{PNDR}_{\mathrm{D}}$, cujas explicações são as mesmas atribuídas às farinhas de carne e sangue.

Com base nestes dados, quanto ao teor de PNDR $_{D}$ ( $\mathrm{g} / \mathrm{kg} \mathrm{MS})$, as farinhas de carne e de sangue seriam as melhores fontes protéicas e o farelo de trigo, o grão de soja, o caroço de algodão e o fubá de milho, as piores.

Comparando os dados dos alimentos da Tabela 2, que são comuns aos citados por CABRAL (1999), pode-se inferir que a utilização dos índices de digestão intestinal de 100,100 e $80 \%$ para as frações $B_{1}, B_{2}$ e $\mathrm{B}_{3}$ que escapam do rúmen conforme SNIFFEN et al. (1992) para estimativa da PNDR $_{\mathrm{D}}$, tendem a superestimar a digestibilidade intestinal de todos alimentos. Este fato pode levar a erros severos de predição da proteína metabolizável e do desempenho animal.

Embora o glúten de milho e o farelo de soja tenham apresentado elevada digestão intestinal da PNDR, alguns autores sugerem que a melhora no desempenho de vacas leiteiras de alta produção, adicionalmente à digestão intestinal, depende do perfil aminoacídico dessas fontes, o qual deve complementar o perfil da proteína microbiana (CHEN et al., 1993; CLARK et al., 1992; SCHWAB et al., 1992; e BRODERICK, 1994).

Resultados de ensaios com infusão de aminoácidos no duodeno têm induzido conclusões de que os aminoácidos lisina (Lys) e metionina (Met) são os primeiros limitantes à produção e à síntese de proteína do leite, a partir dos quais tem sido sugerido que a quantidade de lisina e metionina, como porcentagem dos aminoácidos essenciais totais na digesta duodenal adequada para a síntese de leite e caseína, seria de 15 e $5 \%$, respectivamente (SCHWAB et al., 1992). Dessa forma, suplementos protéicos pobres ou desbalanceados em lisina e metionina poderiam resultar na falta de resposta ou redução na produção de leite e na quantidade de proteína secretada (SCHWAB et al., 1992).

Quando as diferentes fontes protéicas são comparadas quanto ao perfil de aminoácidos observados por SCHWAB et al. (1992b), pode-se inferir que a fonte protéica de melhor qualidade é a proteína microbiana, cujos perfil em aminoácidos e relação lisina:metionina se assemelham aos da proteína do leite. O glúten de milho, apesar de ter digestibilidade intestinal semelhante à do farelo de soja, apresenta sério desbalanceamento na proporção lisina:metionina, pois é excelente fonte de metionina, mas é pobre em lisina. Já o farelo de soja apresenta concentração média em lisina e de média a baixa em metionina, mas mantém o balanço nas proporções destes aminoácidos. Dessa forma, o farelo de soja pode ser considerado 


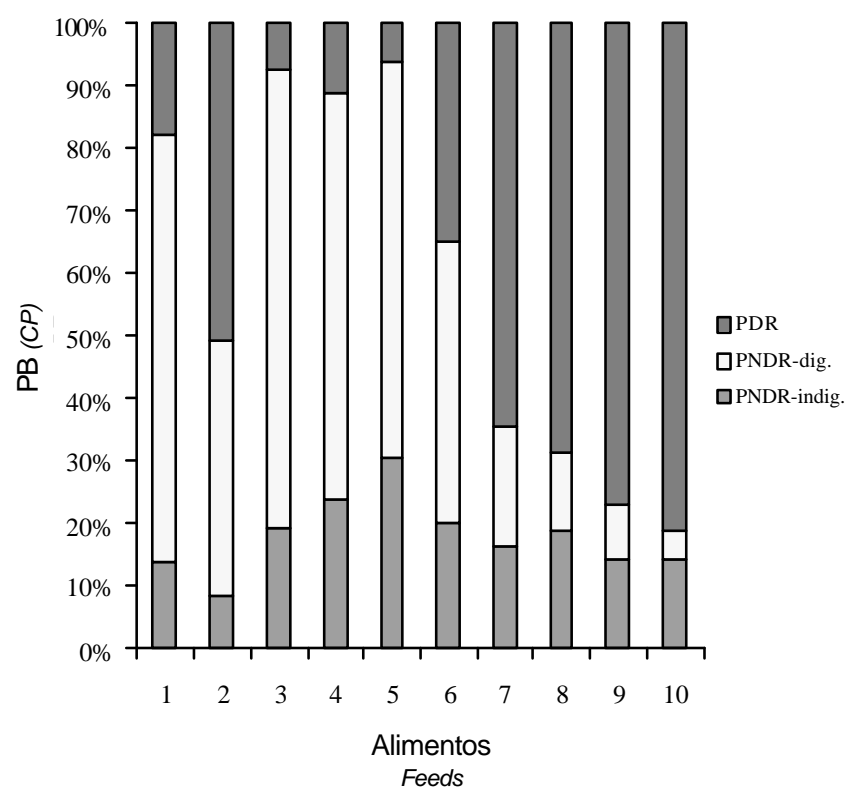

Figura 2 - Proporções relativas da proteína degradada no rúmen (PDR), e da proteína não-degradada no rúmen digestível (PNDRdig.) e da proteína nãodegradada no rúmen indigestível (PNDRindig.) no intestino delgado, do glúten de milho (1), farelo de soja (2), farinha de carne (3), farinha de peixe (4), farinha de sangue (5), fubá de milho (6), farelo de algodão (7), caroço de algodão (8), farelo de trigo (9) e grão de soja (10).

Figure 2 - Relative proportions of rumen-degradable protein, rumen-undegradable protein digestible and of rumenundegradable protein indigestible in small intestine from corn gluten meal (1), soybean meal (2), mea meal (3), fish meal (4), blood meal (5) corn meal (6), cottonseed meal (7), whole raw cottonseed (8), wheat middlings (9) and whole raw soybean (10).

como fonte protéica de melhor qualidade que o glúten de milho.

A farinha de peixe, entre os suplementos protéicos, é o único que possui balanço equilibrado em lisina e metionina, por isso, é o suplemento mais provável de promover melhora no balanço destes aminoácidos no duodeno e exercer efeito positivo no desempenho de vacas leiteiras. Entretanto, apesar de sua digestibilidade intestinal não ser tão alta quanto à do farelo de soja, apresenta grande variação na digestibilidade de acordo com os dados da literatura, a qual é dependente da matéria-prima e do seu processamento. A farinha de sangue é rica em lisina, mas pobre em metionina. A farinha de carne, semelhantemente ao farelo de soja, apresenta con- centração intermediária em lisina e de pobre a intermediária em metionina, mas não apresenta sério desbalanço na proporção destes aminoácidos (SCHWAB et al., 1992a).

A superioridade do farelo de soja quanto à qualidade de sua proteína tem sido comprovada em estudos nos quais este suplemento tem sido substituído por fontes de elevado escape do rúmen, resultando em redução da síntese de proteína microbiana e do seu fluxo para o intestino delgado. Em virtude de a proteína microbiana ser a melhor fonte de lisina e metionina, normalmente não têm sido verificados benefícios pela suplementação com estas fontes (SANTOS et al., 1998). Dessa forma, o aumento da PNDR da dieta, por meio da completa substituição do farelo de soja pelo glúten de milho, tem resultado em efeito negativo no desempenho de vacas leiteiras, principalmente em dietas à base de silagem de milho, cuja proteína, assim como a do glúten, é pobre em lisina (SANTOS et al., 1998).

A comparação entre os alimentos estudados e os avaliados pelos diversos autores torna-se difícil, uma vez que os métodos de processamento, bem como sua composição, podem ser diferentes, podendo afetar tanto a degradação no rúmen, quanto a digestibilidade intestinal da proteína.

Embora os sistemas para formulação de dietas considerem que a PNDR apresenta digestibilidade intestinal constante, os resultados encontrados neste estudo mostram o contrário, devendo ser considerado durante a escolha por fontes de PNDR, bem como durante a formulação de dietas. Os valores de digestão intestinal da PNDR, em combinação com as estimativas da degradação ruminal da proteína, podem fornecer estimativas da proteína metabolizável de ingredientes individuais da dieta. Embora os dados obtidos para alguns alimentos não correspondam aos valores relatados pela literatura, deve-se ressaltar que os alimentos produzidos no Brasil apresentam valor nutricional diferente daqueles produzidos sob condições temperadas e, aliado a isto, diferenciam-se, também, quanto ao tipo de processamento, podendo implicar em diferenças, inclusive, entre regiões.

\section{Conclusões}

O glúten de milho e o farelo de soja foram os alimentos que propiciaram a melhor digestibilidade intestinal e o grão de soja e o farelo de trigo, a pior. Adicionalmente à digestibilidade intestinal, o perfil de aminoácidos dos suplementos protéicos deve ser 
552 Rev. bras. zootec.

considerado para formulação de dietas para animais de elevado desempenho.

Embora alguns sistemas de adequação de dietas para ruminantes considerem que a PNDR apresenta digestibilidade intestinal constante, os resultados encontrados neste estudo sugerem que esta é variável.

\section{Referências Bibliográficas}

AGRICULTURAL AND FOOD RESEARCH COUNCIL AFRC. 1993. Energy and protein requirements of ruminants. Wallingford, UK: CAB International. 159p.

ASSOCIATION OF OFFICIAL ANALYTICAL CHEMISTS - AOAC. 1990. Official methods of analysis. 15.ed., Arlington, Virginia. $1117 \mathrm{p}$.

BRODERICK, G.A. Methodology for the determining ruminal degradability of feed proteins. In: SIMPÓSIO INTERNACIONAL SOBRE EXIGÊNCIAS NUTRICIONAIS DE RUMINANTES. Viçosa, 1995. Anais... Viçosa: UFV/DZO. 1995. p.139-176.

BRODERICK, G.A. Quantifying forage protein quality. In: NATIONAL CONFERENCE ONFORAGE QUALITY, EVALUATION, AND UTILIZATION, 1994, Lincoln. Proceedings...Lincoln: University of Nebrasca, 1994. p.200-228.

CABRAL, L.S. Cinética ruminal das frações de carboidratos e proteínas e digestão intestinal da proteína de alimentos por intermédio de técnicas in vitro. Viçosa, MG:UFV, 1999. 74p. Dissertação (Mestrado em Zootecnia) - Universidade Federal de Viçosa, 1999.

CALSAMIGLIA, S., STERN, M. D. 1995. A three-stepinvitro procedure for estimating intestinal digestion of protein ruminants. J. Anim. Sci., 73(5):1459-1465.

CHEN, K.H., HUBER, J.T., THEURER, C.B. et al. 1993. Effect of protein quality and evaporative cooling on lactational performance of Holstein cows in hot weather.J. Dairy Sci., 76(3):819-825.

CLARK, J.H., KLUSMEYER., T.H., CAMERON, M.A. 1992. Microbial protein sinthesys and flows of nitrogen fractions to the duodenum of dairy cows. J. Dairy Sci., 75(8):2304-2323.

DE BOER, G., MURPHY, J.J., KENNELLY, J.J. 1987. Mobile nylon bag for intestinal availability of rumen undegradable protein. J. Dairy Sci., 70(5):977-982.

ERASMUS, L.J., BOTHA, P.M., CRUYWAGEN, C.W. 1994. Amino acid profile and intestinal digestibility in dairy cows of rumen-undegradable protein from feedstuffs. J. Dairy Sci., 77(2):541-551.

FALDET, M.A., VOSS, V.L., BRODERICK, G.A. et al. 1991. Chemical, in vitro and in situ evaluation of heat-treated soybean proteins. J. Anim. Sci., 74(8):2548-2554.

GOERING, F.K., GORDON, C.H., HEMKEN, R.W. et al. 1972. Analytical estimatives of nitrogen digestibility in heat damaged forages. J. Dairy Sci., 55(9):1275-1280.

HVELPLUND, T. 1985. Digestibility of rumen microbial protein and undegraded dietary protein estimated in the small intestine of sheep and by in saco procedure. Acta Agric. Scand. (Suppl.), 25:132.

MASOERO, F., FIORENTINI, L., ROSSI, F. et al. 1994. Determination of nitrogen intestinal digestibility in ruminants. Anim. Feed Sci. Technol., 48(3,4):237-264.
MORENZ, M.J.F., MALAFAIA, P.A.M., COELHO DA SILVA, J.F. et al. Estimativa do escape protéico por técnica in situ e pela utilização de proteases comerciais. In: REUNIÃO ANUAL DA SOCIEDADE BRASILEIRA DE ZOOTECNIA, 34, 1998, Botucatu. Anais... Botucatu: SBZ, 1998. p.284-286.

NATIONAL RESEARCH COUNCIL - NRC. 1985. Ruminant nitrogen usage. Washington DC. $158 \mathrm{p}$.

NOCEK, J.E. 1988. In situ and other methods to estimate ruminal protein and energy digestibility: a review. J. Dairy Sci., 71(8):2051-2069.

RAMOS, S.M., VALADARES FILHO, S.C., COELHO DA SILVA, J.F. et al. 1996. Utilização da técnica do saco de náilon móvel para a determinação da digestibilidade intestinal de vários alimentos, em novilhos cecectomizados. R. Bras. Zootec., 25(4):778-793.

SANTOS, F.A.P., SANTOS, J.E.P., THEURER, C.B. et al. 1998. Effects of rumen-undegradable protein on dairy cow performance: A 12-year literature Review. J. Dairy Sci., 81(12):3182-3213.

SCHWAB, C.G., BOZAC, C.K., WHITEHOUSE, N.L. et al. 1992a. Amino acid limitation and flow to duodenum at four stages of lactation. 1. Sequence of lysine and metionine limitation. J. Dairy Sci., 75(12):3486-3502.

SCHWAB, C.G., BOZAC, C.K., WHITEHOUSE, N.L. et al. 1992b. Amino acid limitation and flow to duodenum at four stages of lactation. 2. Extent of lysine limitation.J. Dairy Sci., 75(12):3503-3518.

SCHWAB, C.G. Amino acid nutrition of dairy cow: current status. In: PROCEEDINGS CORNELL NUTRITION CONFERENCE FOR FEED MANUFACTURES. 1996, Ithaca. Proceedings... Ithaca: Cornell University, 1996. p.184-198.

STERN, M.D., CALSAMIGLIA, S., ENDRES, M.I. Dynamics of ruminal nitrogen metabolism and their impact on intestinal protein supply. In: PROCEEDINGS CORNELL NUTRITION CONFERENCE FOR FEED MANUFACTURES. 1994, Ithaca. Proceedings... Ithaca: Cornell University, 1994. p.105-116.

VALADARES FILHO, S.C. Digestão pós-ruminal de proteínas e exigências de aminoácidos para ruminantes. In: SIMPÓSIO INTERNACIONAL DE DIGESTIBILIDADE EM RUMINANTES, 1997, Lavras. Anais... Lavras: UFLA/FAEPE, 1997. p.87-113.

VAN SOEST, P.J. 1994. Nutritional ecology of the ruminant. New York: Cornell University Press. Ithaca. 476p.
Recebido em: 27/06/00 Aceito em: 04/10/00 